\begin{tabular}{|c|c|c|}
\hline ב & $\begin{array}{l}\text { International Journal of Current Research in } \\
\text { Biosciences and Plant Biology }\end{array}$ & \\
\hline & Volume $4 \bullet$ Number 6 (June-2017)• ISSN: 2349-8080 (Online) & \\
\hline $\begin{array}{l}\text { EXCELLEN } \\
\text { PUBLISHERS }\end{array}$ & Journal homepage: www.ijcrbp.com & \\
\hline
\end{tabular}

\title{
Biological and Phytochemical Study of "Thymus vulgaris" Used in the Phytotherapy in the Deba-Relizane Region (West Algeria)
}

\author{
Ahmed BENDJILALI*
}

Department of Plant Physiology, College of Biologie, Institute of Natural Science, University Ahmed Benbella, Oran, Algeria

*Corresponding author.

\begin{tabular}{|c|c|}
\hline Abstract & Article Info \\
\hline 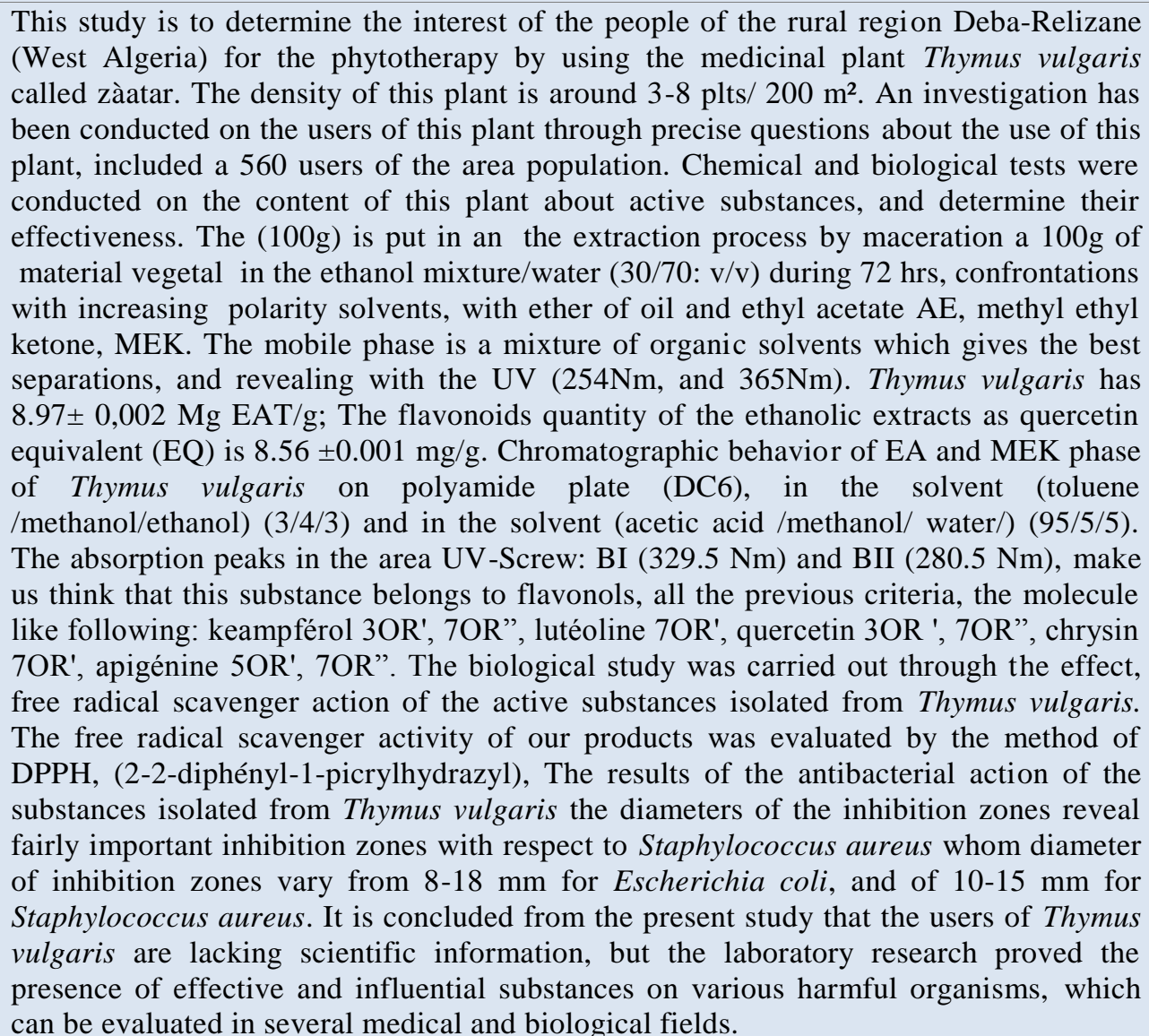 & $\begin{array}{l}\text { Accepted: 08 May } 2017 \\
\text { Available Online: 06 June } 2017 \\
\text { Key w or ds } \\
\text { Keampférol } \\
\text { Lutéoline } \\
\text { Medical plant } \\
\text { Phytotherpy } \\
\text { Relizane } \\
\text { Thymus vulgaris }\end{array}$ \\
\hline
\end{tabular}

A. Bendjilali (2017) / Biological and Phytochemical Study of "Thymus vulgaris" Used in the Phytotherapy in the Deba-Relizane Region 


\section{Introduction}

The purpose of our study is to determine the interest of the people of the rural region Kalàa for the phytotherapy by using the medicinal plant Thymus vulgaris called zàatar, in spite of the availability of modern health care. This mountain village is located at $35 \mathrm{~km}$ in the southwest of the City of Relizane (Algeria), in an altitude of $517 \mathrm{~m}$. The low rate of infectious diseases in the population, and the high density of this plant (around 3-8 plants $/ \mathrm{m}^{2}$ every each $200 \mathrm{~m}$ ) are the reasons why the present study is run, as biologists, a process of investigation over the users and made a phytochemical study on this plant.

\section{Materials and methods}

\section{Investigation}

A series of questions were prepared about the use of this plant, parts used, method, treated disease, duration, sex, age, occupation and educational level of the users. This investigation included 860 users of people in the area population.

\section{Vegetable material}

Vegetable material was made up by the superficial parts of plant Thymus vulgaris. The Thyme sheets were gathered in May 2016 in the Kalàa region (Algeria). After drying it with ambient air without light exposition, in order to preserve to the maximum the integrity of chemical substances, vegetable material is crushed coarsely in an electric mill.

\section{Photochemical study}

The crushed vegetable material $(100 \mathrm{~g})$ was put in an extraction process by maceration in the ethanol mixture/water (30/70: v/v) during 72 hrs. Macerated extracts were joined together then filtered and evaporated. The dry residue was included in $100 \mathrm{ml}$ of boiling distilled water. After a decantation, the limpid phase was undergone confrontations with increasing polarity solvents, with either of oil and ethyl acetate AE, methyl ethyl ketone, MEK.

Various recovered phases (acetate of ethyl, MEK, phase free water) are dryly evaporated then taken again by $10 \mathrm{ml}$ of methanol, the extracts obtained are then stored with a room at ambient air until their use.

\section{The analytical chromatography on thin layer}

The driving of a sample dissolved by a mobile phase through a stationary phase was done. Polyamide plates (DC6) are prepared by mixing $10 \mathrm{~g}$ of polyamide powder in $50 \mathrm{ml}$ of ethanol. The mobile phase is a mixture of organic solvents which gives the best separations.

\section{Revealing with the UV}

That makes possible to highlight spot shaped substances which absorb UV between $254 \mathrm{Nm}$ and $365 \mathrm{Nm}$.

\section{Revealing by chemical methods}

These methods consist in bringing in contact plate with a more or less specific reagent. It gives a product colored by chemical reaction with the substances to reveal (Latifou, 2005)

\section{Biological activities}

Free radical scavenger activity: The DPPH is a stable free radical which has a band of absorbance at $517 \mathrm{Nm}$. It is used to evaluate the antioxidant activity. Methodology is based on the decrease of the absorbance of a methanolic solution of DPPH following the addition of the antioxidant (Bernardi et al., 2007). In the present study active ingredients of the extracts of Thymus vulgaris was used. These extracts were dryly evaporated and then inserted into the methanol in order to have concentrations of $5 \mathrm{mg} / \mathrm{ml}$ for each one. The free radical activity of these extracts was measured according to the method described by Es-Safi et al. (2007): $25 \mu$ of the extract was tested with $2.5 \mathrm{ml}$ of a methanolic solution of DPPH $(0,004 \%)$. The optical density $\mathrm{C}$ was measured by the SHIMADZU spectrophotometer to $517 \mathrm{~nm}$, after 30 minutes of incubation in ambient air temperature room in the darkness. Antibacterial activity test of susceptibility was carried out according to the method of diffusion of the discs described by Dulger and Gonuz (2004), Parekh and Chanda (2007) and Rota et al. (2008). The microbial support was composed of Escherichia coli, Staphylococcus aureus, Enterobacter spp., those were isolated from laboratory of Microbiology, University of Oran. The various bacterial species were multiplied by streak method, incubated at $37^{\circ} \mathrm{C}$ in order to obtain isolated colonies used for the preparation of the inoculum. The colonies were taken in $10 \mathrm{ml}$ of nutritive stock then carried to incubation for $18-24 \mathrm{hrs}$ at $37^{\circ} \mathrm{C}$. The sterile paper discs Wattman 
No. 1 (6 mm diameter) were filled of the extract natural to test. The methanol impregnated discs were also used as negative control sample: the agar of Muller Hinton (2 $\mathrm{mm}$ ) thickness run in limp of kneaded sterile of $90 \mathrm{~mm}$ $\phi$. Discs to be tested were first deposited on the surface of inoculated agar. The antibacterial activity was given in term of diameter of the zone of inhibition produced around the discs after $24 \mathrm{hrs}$ of incubation at $37^{\circ} \mathrm{C}$.

\section{Results and discussion}

\section{Investigation}

It is concluded through this research in the field, that Thymus vulgaris is a medicinal herb among 280 species in Algeria, with a therapeutic aim, in green form or dry (spices), and that $73.4 \%$ of the medicinal herbs are delivered by the herbalists, and $14.3 \%$ by the apothecaries, $7.1 \%$ of the pharmacists and $5.2 \%$ by Clergyman. The results show that most of the people use this plant more for treating the diseases, than as spices or for aromatizing. It seems clear that this plant is designed to cure, for daily uses. Eighty percent of the world's population uses medicinal plants, $13 \%$ to $17 \%$ of 422000 sub-plant species (Léger, 2008). About 68\% of the users in the present study utilized Thymus vulgaris for treatments (Fig.1).

utilisationAd TISHymus

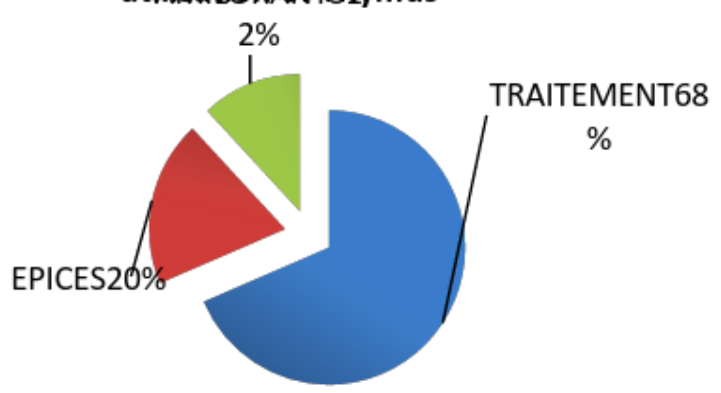

Fig. 1: Utilization of Thymus vulgaris.

Although this area is known for the rate of illiteracy, we note that the educated class move towards this kind of drug, indicating the interest of the natural therapy and chemical treatment. About $80 \%$ of the world's population depends directly on medicinal plants for its health care, partly because of an inadequate supply of allopathic medicines reserved mainly for the populations of western countries (Hamilton, 2003). The scientific level of the users in the present study is shown in Fig.2 which showed a higher percentage $(53 \%)$ of users of Thymus vulgaris are at primary level.

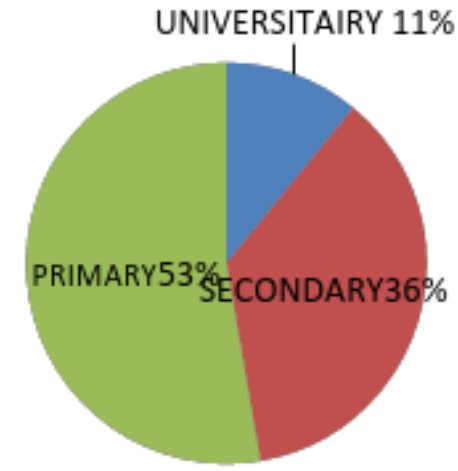

Fig. 2: Scientific level of the users of Thymus vulgaris.

In case of present study population, major use of Thymus vulgaris was found to be used for the ailment of digestive system (65\%) followed by digestive system (Fig. 3). Most of the people use the medicinal herbs for common diseases, such as the respiratory and digestive diseases. These results prove that the practice dominates this kind of treatment. In the United Kingdom, for example, patients are referred to the Royal London Hospital for Integrated Medicine because other treatments have failed it is the patient's personal or that other treatments had undesirable effects. In Australia, interviews with Traditional medicine MT and complementary medicine $\mathrm{CM}$ users reveal that the failure of conventional treatments and the desire for a healthy lifestyle are the two main reasons for the use of TM / MC (Williamson, 2008).

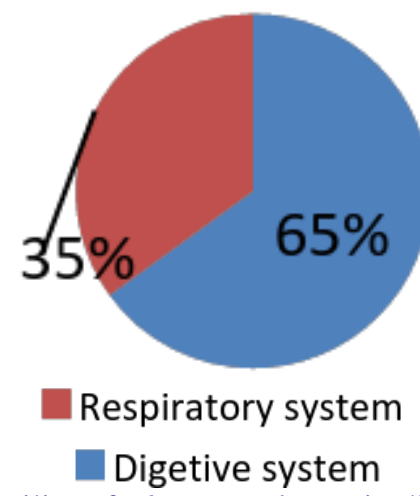

Fig. 3: Major utility of Thymus vulgaris in disease treatment.

There are disparities in the use of the plants, $35.6 \%$ dried plants, $40.9 \%$ fertile plants, $21.43 \%$ without knowledge, $75 \%$ use the wild plants, $25 \%$ the crop plants, $74 \%$ use the leaves, $21 \%$ whole plants, $5 \%$ the roots (Fig. 4). This statistical information indicates the absence of the culture and knowledge scientists of this medicinal herb. Many turn to traditional medicine MT and complementary medicine $\mathrm{CM}$ products and 
practices by considering that what is natural is safe (WHO, 2004).

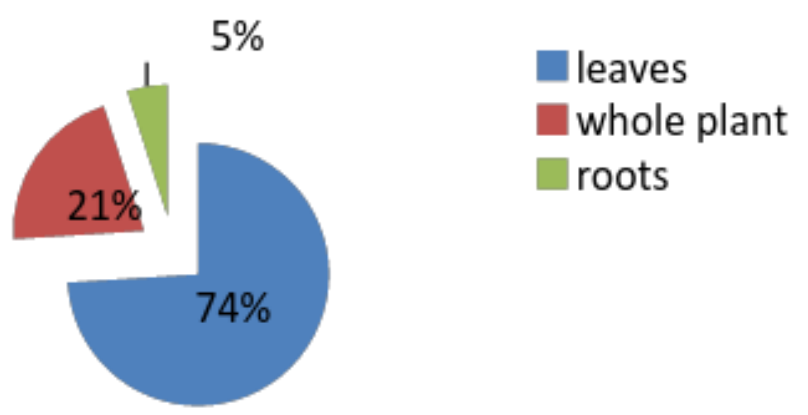

Fig. 4: Used parts of Thymus vulgaris.

\section{Phytochemical study}

The extraction of the superficial parts of Thymus vulgaris by maceration in the ethanol mixture/water (30/70: v/v) and the partitioning with various solvents enabled us to obtain several phases: Ether of oil, contains only fat, chlorophylls, and impurities. Ethyl Acetate (EA) phase: it allows extracting the flavonoids by involving the aglycones. Methyl ethyl ketone (MEK) phase: an analytical chromatography on thin layer was done by using two fairly polar solvents systems. Under light $\mathrm{UV}$ at $365 \mathrm{Nm}$, the analysis of thin layer chromatography revealed the presence of flavones and flavonols. Chromatographic behavior of EA and MEK phase of Thymus vulgaris on polyamide plate (DC6), in the solvent (toluene /methanol/ethanol) (3/4/3) and in the solvent (acetic methanol/acid water/) (95/5/5), with black fluorescence under $365 \mathrm{Nm}$ UV of molecule 1 and the absorption peaks in the area UV-Screw: BI $(329.5 \mathrm{Nm})$ and BII $(280.5 \mathrm{Nm})$, make us think that this substance belongs to flavonols (substituted 3-OH). According to all the previous criteria, we propose a schematization of the molecule like following: keampférol 3OR', 7OR", lutéoline 7OR', quercetin 3OR', 7OR", chrysin 7OR' and apigénine 5OR', 7OR".

The phenolic compounds were determined by the method of Folin ciocalteu. Thymus vulgaris has $8.97 \pm$ $0.002 \mathrm{Mg} \mathrm{EAT} / \mathrm{g}$ of dry extract of the plant. The flavonoids quantity of the ethanolic extracts as quercetin equivalent (EQ) is $8.56 \pm 0.001 \mathrm{mg} / \mathrm{g}$, EQ for the dry extract of Thymus vulgaris.

The quantity of the phenolic compounds of the ethanolic extracts of the studied plants depends mainly on their origin (Ebrahimzadeh et al., 2008), variety, the season of culture, the season of harvest, the climatic conditions and environmental, the geographical location, the various diseases which can affect the plant, the maturity of the plant (Park and Cha, 2003). The natural antioxidants are present in the food. Most of them are phenolic compounds which have at least an aromatic nucleus, containing one or more substituents. Indeed this antioxidant property is in direct relationship with the structure of these molecules (Cosio et al., 2006).

Thymus vulgaris is composed of volatile oil $0,4-1 \%$, thymol, carvacrol and paracymene. It is a disinfectant medical because it contains thymol. The use of its oil outside and inside is good for the respiratory, gastrointestinal, and disinfecting, anti-belch (El-Sayed and Hussein, 2004). As a consequence, the medicinal herbs are strategic materials, very important in pharmaceutical industry and represent a significant role in its production (El-Abed, 2009). The active chemical substances have a secondary effect for the plant and an important physiological effect on human being. These chemical products are in the all parts of the plant, for which the scientists studied the chemistry of the drugs and research the ways of extinction of these products for their effects on human physiology (Hijawi et al., 1999).

\section{Biological study}

The free radical scavenger activity isolated from Thymus vulgaris of our products was evaluated by the method of DPPH. A methanolic solution of DPPH • (2-2-diphényl1-picrylhydrazyl) presents a violet sink color in presence of an antioxidant. The reduced form of DPPH-H confers on solution a yellow coloring, and consequently a reduction in the absorbance (Perez et al., 2007), DPHH (purple) and flavonoid give DPHH (yellow) with flavonoid radical phenoxyl Trapping of DPPH by flavonoids (pH: phenolic core) (Amić et al., 2003). The results confirm the percentages of the free radical activity of the main flavonoid isolated from Thymus vulgaris is classified according to the following decreasing order: standard quercetin $(93.05 \%)$, quercetin 3 OR' 7 OR' '(70.45\%), lutéoline (58.30\%), lutéoline 7OR' (52.58\%), kempférol 3OR' 7OR" (50.17\%), apigénine' 7OR" (50.96\%), chrysin 7OR' (5.66\%) with respect to free radical DPPH.

The antibacterial action of the substances isolated from Thymus vulgaris, the results of the diameters of the inhibition zones reveal that Escherichia coli seems sensitive to the tested flavonoids. These same flavonoids develop fairly important inhibition zones with respect to 
Staphylococcus aureus whom diameters inhibition zones vary between 8 and $18 \mathrm{~mm}$ for Escherichia coli, and of 10 and $15 \mathrm{~mm}$ for Staphylococcus aureus. The sensitivity of Escherichia coli and of Staphylococcus aureus shows the antibacterial action of the flavonoids. In fact, this sensitivity is in relation with the number of free hydroxyls. Thymus vulgaris develops inhibition zones equivalent to $15 \mathrm{~mm}$ for Staphylococcus aureus and $18 \mathrm{~mm}$ for Escherichia coli. Cowan (1999) supposed that the flavonoids deprived of the free groupings hydroxyls have more antimicrobial activity compared to those which are equipped with it, which leads to an increase in their chemical affinity to the membrane lipids. Therefore we can suppose that the microbial target of these tested flavonoids is the cytoplasmic membrane. The sensitivity of Escherichia coli and of Staphylococcus aureus flavonoids tested or a less action, and even worthless on another (the resistance of Enterobacter species). The antibacterial activity of the flavonoids can be explained by the mechanism of toxicity with respect to the microorganisms which is done that is to say by nonspecific interactions such as establishment of the bridges hydrogen with proteins of the cellular walls or the enzymes, chelation of the metal ions, inhibition of the bacterial metabolism, the sequestration of substances necessary for the growth of the bacteria (Karou et al., 2005). The results of the study on Thymus vulgaris against resistant Staphylococcus bacteria showed antimicrobial activity against microorganisms in particular against the bacteria $(\mathrm{Gram}+),(\mathrm{Gram} \rightarrow)$, and the strong component responsible in thyme is thymol (Tohidpour et al., 2010).

\section{Conclusion}

Thymus vulgaris is a medicinal herb among 280 species in Algeria, with a therapeutic aim. The educated class, distinguished, and conscious of the phytotherapy and the chemical treatment but the users are completely ignorant of the scientific method and information in the use of this plant. The medicinal herb Thymus vulgaris remains always the reliable source of the active ingredients known by their therapeutic properties. The qualitative analyses done with chromatography under UV the presence of a multiplicity of varieties of phenolic compounds. It reveals the presence of the fairly large quantities out of polyphenols. Those are partitioned by various techniques in flavones and flavonols. These flavonoids has a good activity, and these substances are considered as first class antioxidant agents and can be employed for therapeutic applications, knowing that the antioxidants contribute in a very effective way to the prevention of the diseases such as cancer, and cardiovascular diseases. During this study we also realized an antibacterial test with respect to some pathogenic germs, the microbiological results showed that flavonoids of Thymus vulgaris reacts clearly on the bacterial tested Escherichia coli, Staphylococcus aureus, Enterobacter species (Gram+), (Gram-). Our country has an immense biodiversity medical plants are characterized by an important tank of secondary metabolites, active substances with therapeutic and pharmacological characteristics. This requires can to be exploited by research in biological and medical aspects, in order for properly and effectively valorisation the medical plants and maintain a healthy ecosystem.

\section{Conflict of interest statement}

Author declares that there is no conflict of interest.

\section{References}

Amić, D., Davidović-Amić, D., Bešlo, D., Trinajstić, N., 2003. Structure-radical scavenging activity relationships of flavonoids. Croat. Chem. Acta. 76(1), 55-61.

Bernardi, A. P. M., López-Alarćon, C., Aspee, A., Rech, S., Von Poser, G. L., Bride, R., Lissp, E., 2007. Antioxidant activity of flavonoids isolated from Hypericum ternum. J. Chilean Chem. Soc. 52(4), 1326-1329.

Cosio, M. S., Buratti, S., Mannino, S., Benedetti, S., 2006. Use of an electrochemical method to evaluate the antioxidant activity of herb extracts from the Labiatae family. Food Chem. 97(4), 725-731.

Cowan, M. M., 1999. Plant products as antimicrobial agents. Clin. Microbiol. Rev. 12(4), 564-570.

Dulger, B., Gonuz, A., 2004. Antimicrobial activity of some Turkish medicinal plants. Pak. J. Biol. Sci. 7(9), 1559-1562.

Ebrahimzadeh, M. A., Pourmmorad, F., Hafezi, S., 2008. Antioxidant activities of Iranian corn silk. Turk. J. Biol. 32, 43-49.

El-Abed, I., 2009. Study of active antioxidant substances for the extract of alkaloids of the Traganum nudatum plant. Master Thesis, University Kasdi Merbah -Ouargla, Algeria.

El-Sayed, Ab. B. M., Hussein, Abd. T., 2004. Encyclopedia of the treatment of herbs and medicinal plants. Dar Alf for Publication and 
Distribution, Egypt. pp.25-55.

Es-Safi, N. E., Kollmann, I., Khlifi, S., Ducrot, P. H., 2007. Antioxidants effect of compounds isolated from Globularia alypum L. structure-activity relationship. LWT-Food Sci. Technol. 40, 12461252.

Hamilton, A., 2003. Medicinal Plants and Conservation: Issues and Aproches. Surrey (Royaume Univ.), International Plants Conservation Unit, WWF-UK. 51p.

Hijawi, G., Hayat, H. M., Rola, M. J. K., 1999. Pharmacology of the Medicinal Plants of the House of Culture for Publication and Distribution, Egypt. pp.5-6.

Karou, D., Dicko, M. H., Simporé, J., Yameogo, S., Sanon, S., Traoré, A. S., 2005. Activités antioxidants and antibacterials of polyphenols extracted from medicinal plants of traditional pharmacopoeia of Burkina Faso. Process Control to Improve Quality of Food, Use of GMO, Agri-food Risk Analysis. 8-11, November. Ouagadougou.

Latifou, L., 2005. Etude phytochimique et activité biologique de substances naturelles isolées de plantes beninoises. Thèse de doctorat de l'université Louis Pasteur de Strasbourg.

Léger, A., 2008. Biodiversity of Quebec medicinal plants and measures to protect biodiversity and the environment memory presented as a partial requirement of the Masters Degree in Environmental
Sciences, Québec University, Montréal.

Parekh, J., Chanda, S. V., 2007. In vitro antimicrobial activity and phytochemical analysis of some Indian medicinal plants. Turk. J. Biol. 31, 53-58.

Park, H. J., Cha, H. C., 2003. Flavonoids from leaves and exocarps of the grape Kyoho. Korean J. Biol. Soc. 7, 327-330.

Pérez, M. B., Calderón, N. L., Croci, C. A., 2007. Radiation-induced enhancement of antioxidant activity in extracts of rosmary (Rosmarinus officinalis L). Food Chem. 104, 585-592.

Rota, M. C., Herrera, A., Martinez, R. M., Sotomayor, J. A., Jordán, M. J., 2008. Antimicrobial activity and chemical composition of Thymus vulgaris, Thymus zygis and Thymus hyemalis essential oils. Food Control. 19, 681-687.

Tohidpour, A., Sattari, M., Omidbaigi, R., Yadegar, A., Nazemi, J., 2010. Antibacterial effect of essential oils from two medicinal plants against Methicillinresistant Staphylococcus aureus (MRSA). Phytomedicine. 17(2), 142-145.

WHO, 2004. World Health Organization Guidelines on Developing Consumer Information on Proper Use of Traditional, Complementary and Alternative Medicine, Genèva.

Williamson, M., 2008. Information Use and Needs of Complementary Medicine Users. Sydney, National Prescribing Service (http://www.nps.org.au/data/ assets).

\section{How to cite this article:}

Bendjilali, A., 2017. Biological and phytochemical study of "Thymus vulgaris" used in the phytotherapy in the DebaRelizane region (West Algeria). Int. J. Curr. Res. Biosci. Plant Biol. 4(6), 1-6.

doi: https://doi.org/10.20546/ijcrbp.2017.406.001 